Supplement of Biogeosciences, 18, 1081-1103, 2021

https://doi.org/10.5194/bg-18-1081-2021-supplement

(C) Author(s) 2021. This work is distributed under

the Creative Commons Attribution 4.0 License.

(c) (1)

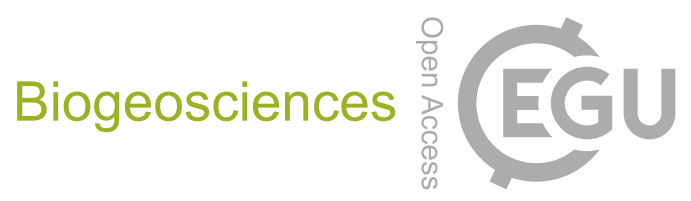

Supplement of

\title{
The transformation of the forest steppe in the lower Danube Plain of southeastern Europe: 6000 years of vegetation and land use dynamics
}

\author{
Angelica Feurdean et al. \\ Correspondence to: Angelica Feurdean (angelica.feurdean@gmail.com, feurdean@em.uni-frankfurt.de)
}

The copyright of individual parts of the supplement might differ from the CC BY 4.0 License. 
Supplement S1. Location of the study area (insert) and the distribution of surface sample sites used for the pollen-based calibration of the vegetation cover shown in the CORINE Land Cover (CLC) map from 2012. Source: CORINE land cover 2012 (CLC2012). For details see Grindean et al., 2019.

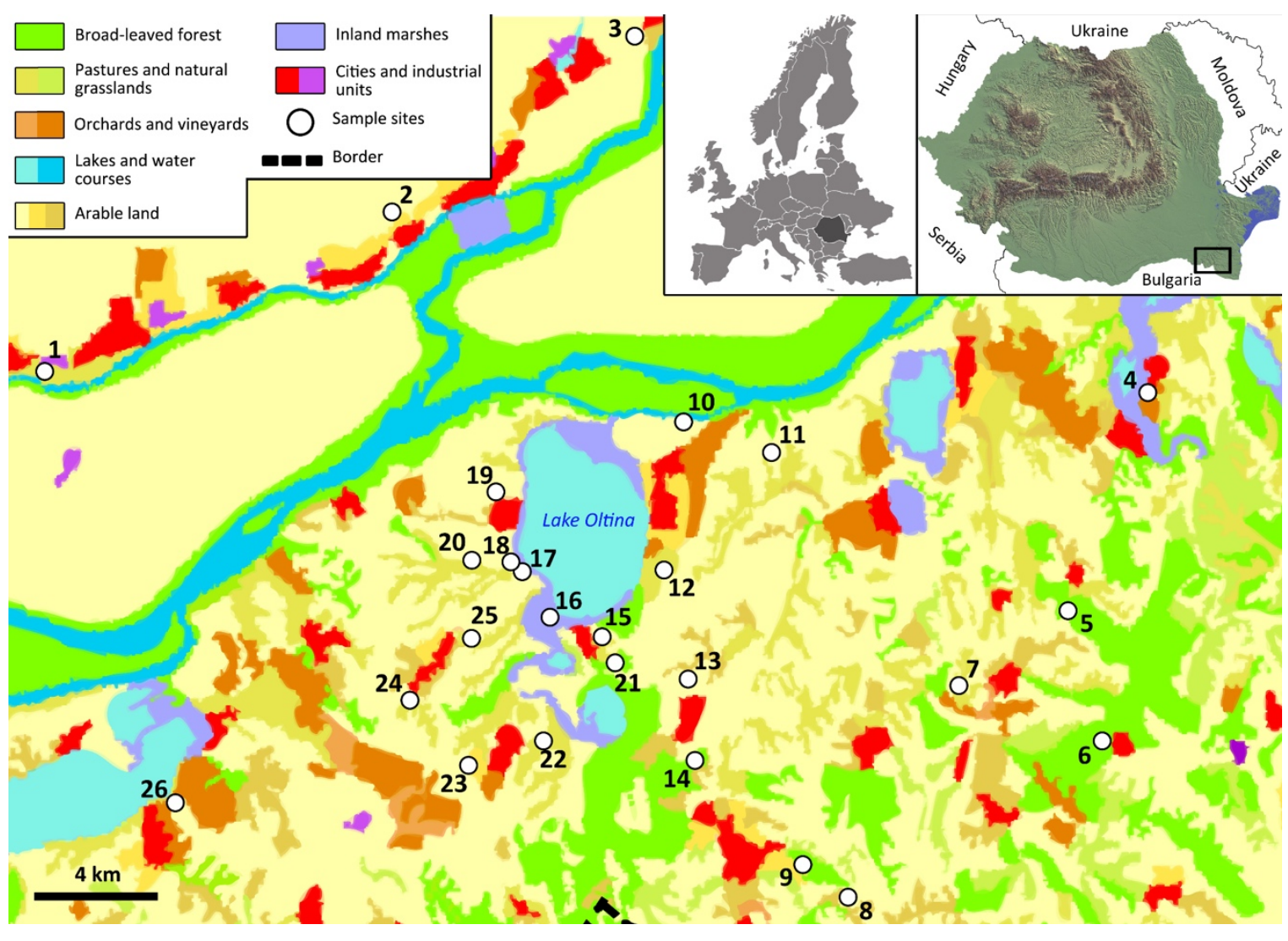

